\title{
Nurses' Knowledge and Practices about Management of Acute Pain among Injured Persons at Kafr El Sheikh General Hospital
}

\author{
Dalia Ramadan Ali Khalifa*Warda Yousseif Mohammed**Yousria Abd ElSalam Seloma** \\ Technical Institute of Nursing- Ministry of Health Khafr Elshiekh- Critical Care and Emergency \\ Nursing, Faculty of Nursing, Cairo University
}

\begin{abstract}
Background: Pain is the most common reason due to which patients come to the emergency department and painful traumatic injuries account for a large portion of emergency department visits. Inadequately managed pain can lead to adverse physical and psychological patient outcomes. Because of the capricious nature of trauma pain, recognition and alleviation of pain, regular assessment and frequent adjustments in medications, dosages, and techniques should be a priority when treating the ill and injured patients. Aim of the study: to assess nurses' knowledge and practices regarding management of acute pain among injured persons at Kafr El Sheikh General Hospital. Research Design: A Descriptive exploratory research design was utilized in the current study. Research questions: a) What do emergency nurses know about management of acute pain among injured persons at Kafr El Skeikh general hospital? b) What are the emergency nurses' practices toward acute pain among injured persons at Kafr El Skeikh general hospital?Setting: The study was carried out at the emergency department in Kafr El sheikh general hospital. Sample: A purposive sample including nursing staff who were working in the emergency department at Kafr El Sheikh general Hospital and were willing to participate in this study(70 nurses).Tools of data collection; Tool 1:Knowledge assessment questionnaire sheet which consist of two parts(a)personal characteristics\& background data.(b)Emergency nurses' knowledge regarding management of acute pain Tool 2: An observational checklist Results: $(91.4 \%)$ of the study sample were females .As Well, $(85.7 \%)$ of them were married .While $(47.1 \%)$ of them were having technical nursing institute degree and $(45.7 \%)$ of them got training courses in emergency courses, the highest mean scores related to causes of acute pain $(0.4333$ out of 1),all the study subjects had unsatisfactory general knowledge about acute pain and hundred percent of the studied sample were having an unsatisfactory practice level in relation to nursing management for acute pain Conclusion: considering the result of the present study and the available evidence it can be concluded that, hundred percent of the studied sample were having an unsatisfactory Knowledge practice level in relation to nursing management for acute pain. Recommendations: based on results of the present study can recommended Hospital decision makers create strategies to decrease work load on nurses and encourage inservices training programs for nurses included knowledge and skills for how to apply assessment and management of patients with acute pain.
\end{abstract}

Key words: Nurses' Knowledge and practices, pain assessment and management.

\section{Introduction}

Pain can be defined as, "An unpleasant sensory and emotional experience associated with actual or potential tissue damage or described in terms of such damage International Association for the study of pain, 2011). Pain is the most common reason due to which patients come to the emergency department. Painful traumatic injuries also 
account for a large portion of emergency department visits. Improved pain management has not only led to increased comfort in trauma patients, but has also been shown to reduce morbidity and improve long-term outcomes.(Cordell et al, 2012).

Various pharmacological options are available for treating acute pain, ranging from oral, intravenous, and intramuscular medications; topical agents; and peripheral nerve blocks. Objectively assessing and documenting a patient's pain is the key to determining treatment(WOLF\&Ma,2013) The approach to a patient with acute pain requires an experienced clinician who is aware of the pharmacology of analgesics and anesthetics, contraindications, precautions, side effects, administration methods, and monitoring

(Wuhrman,Cooney2011).

Insufficient pain control, has been correlated with a catabolic stress responses well as increased incidences of venous thromboembolic events, pulmonary complications, and immunosuppression. Therefore, comprehensive pain assessment is one of the most important initial steps for successful management of acute pain in trauma patients and prevention of these complications.(Toddy et al,2007).

Acute pain in trauma patients results from tissue damage mainly due to excessive nociception which is usually caused by combination of various stimuli, mechanical thermal or chemical secondary to an inflammatory reaction, a trauma or a visceral lesion. This stimuli cause release of chemical substances (histamine, brady kinin, serotonin, substance $P$ ) that activate nociceptors. Once stimulated, a nociceptor transmits a signal along the spinal cord to the brain and causes nociceptive pain(Williams, 2012).

The primary aim of acute pain management in trauma patients is to minimize pain through the careful use of drugs and pain interventions, improve function and increase quality of life while avoiding side effects(Wong,2012). There are a variety of different therapies and techniques available for acute pain relief which arises from multidisciplinary approach. This multi-modal approach usually includes pharmacological interventions with conventional analgesics, but the use the regional anaesthetic techniques, adjuvant agents and nonpharmacological methods can also be very useful in acute pain management in emergency department(Ready\&Edwards,2012)

\section{Significance of the study}

Literature review cited that pain is considered the fifth vital signs. The assessment of pain should be as automatic as taking patient's blood pressure and pulse. Therefore this research will be carried out in an attempt to provide data base about nurses 'knowledge \&practices related to acute pain management among injured persons that can be utilized by health care professionals in the provision of the future care for such group of people.

It has been observed over a period of 4 years of working as a clinical instructor at Kafr El Sheikh General Hospital that many injured persons admitted to emergency department with acute pain develop problems/ complications as increase heart rate, blood pressure, increases myocardial oxygen demand and increase the risk of cardiac is chemia which might be life threatening and consequently prolong patient's hospital stay, and increase hospital costs. Therefore, this study was designed in an attempt to assess nurses' knowledge \& practices related to acute pain management among injured persons at Kafr El Sheikh General Hospital.

Furthermore, this research could be beneficial in maintaining a cost- effective patient care especially in such group of patients as it might shorten hospital stay and safeguard patients against any of life 
threatening complications. and it is hoped that, this effort will generate an attention and motivation for further investigations into this area.

\section{Aim of the study}

The aim of this study was to assess nurses' knowledge and practices regarding management of acute pain among injured persons at Kafr El Sheikh General Hospital.

\section{Research questions}

To fulfill the aim of this study the following research questions were formulated:

1. What do emergency nurses know about management of acute pain among injured persons at KafrElSkeikh general hospital?

2. What are the emergency nurses' practices toward acute pain among injured persons atKafrElSkeikh general hospital?

\section{Subjects and Method}

\section{Research Design}

Descriptive exploratory research design was utilized in the current study.

\section{Setting}

The study was carried out at the emergency department in Kafr El sheikh general hospital

\section{Subjects}

A purposive sample including all nursing staff (70 nurse) who are working in the emergency departments at Kafr El
Sheikh general Hospital and were willing to participate in this study, were included( the hospital contain in each departement emergency room to receive the patient will stay some houres needs to the observation ).

\section{Tools}

1) Knowledge assessment questionnaire sheet:

Which was developed based on review of literature to assess the nurse's knowledge about management of acute pain among injured persons; it consisted of two parts:

A) Personal characteristics \& back ground data of the nurses working in the emergency units. Consisted of 9 items including ( code, age, gender, marital status, years of graduation, level of education, years of experience, years of working in ER, training courses he or she received ).

B ) Emergency nurses' knowledge regarding management of acute pain : It is an Arabic questionnaire sheet developed based on review of literature to assess the nurses knowledge about management of acute pain among injured persons, It consists of 37 Questions.

- General Knowledge about acute pain.(questions from 1-4) '

- Causes of acute pain (questions from 5-7)

- Factors affecting acute pain(questions from 8-13)

- Signs and Symptoms of acute pain (questions from 14-15)

- Effect of the acute pain on the body system (16-20) 
- Medical management of acute pain (2127)

- Nursing Management of acute pain (28-34)

- The complication of acute pain(35-37)

\section{Scoring system}

Each right action was given one score with total score of (37).less than 80\% (30 grades) was considered unsatisfactory while equal or more than $80 \%$ was considered satisfactory

\section{2) An Observational checklist}

The nurse's performances checklist(this sheet was developed by ( Gélinas,2014) to assess emergency nurses' practices during assessment and management of injured persons with acute pain.

\section{Scoring system}

Each right answer was given one score with total score of (29).less than $80 \%$ was considered unsatisfactory while, equal or more than $80 \%$ was considered satisfactory.

\section{Pilot study:}

A pilot study was conducted on 7 nurses to ensure objectivity, clarity, feasibility,validity and reliability of the study tools and determine the time required to fill data collection tools. No modifications were done so the pilot study sample was included in the actual study.

\section{Legal and Ethical Considerations:}

An official permission to conduct the study was obtained from the Ethical Committee of Faculty of Nursing and directors of (Emergency) Care Units. Verbal consents were obtained from head nurses of these units. In addition, nurses' agreements to be included in the study were obtained formally after explanation of the nature and purpose of the study. Each nurse was free to either participate or not in this study and have the right to withdraw from the study at any time without any rational; also, nurses were informed that data will not be included in any further researches without another new consent if they do not mind. Confidentiality and anonymity of each subject were assured through coding of all data.

\section{Statistical Design:}

Upon completion of the data collection, descriptive and inferential statistics were utilized, using the Statistical Package for the Social Sciences (SPSS) program.

Data obtained from the study tools were categorized, tabulated, analyzed and data entry was performed using the SPSS software .Descriptive statistics were applied (e.g. mean, standard deviation, frequency and percentage ) .

\section{Field Work:}

The study was carried out at the Emergency Department in Kafr El Sheikh General Hospital .It is one of the largest hospital in kafer El sheikh City it receives the largest number of patients all over the governor especially those who are in need for special care. This hospital consists of four floors each one has different department, the emergency department consists of 6 rooms each one containing 8 beds one room male, female, orthopedic, obstetrics, pediatric , and ICU room plus each department contains separated observational room to receive the patients Who stay many hours. 
Nurses' Knowledge and Practices about Management of Acute Pain among Injured Persons at Kafr El Sheikh General Hospital

Results:

As regard to Personal characteristics data results:

Table (1) : Percentage distribution of the study sample according to their personal characteristics $(n=70)$

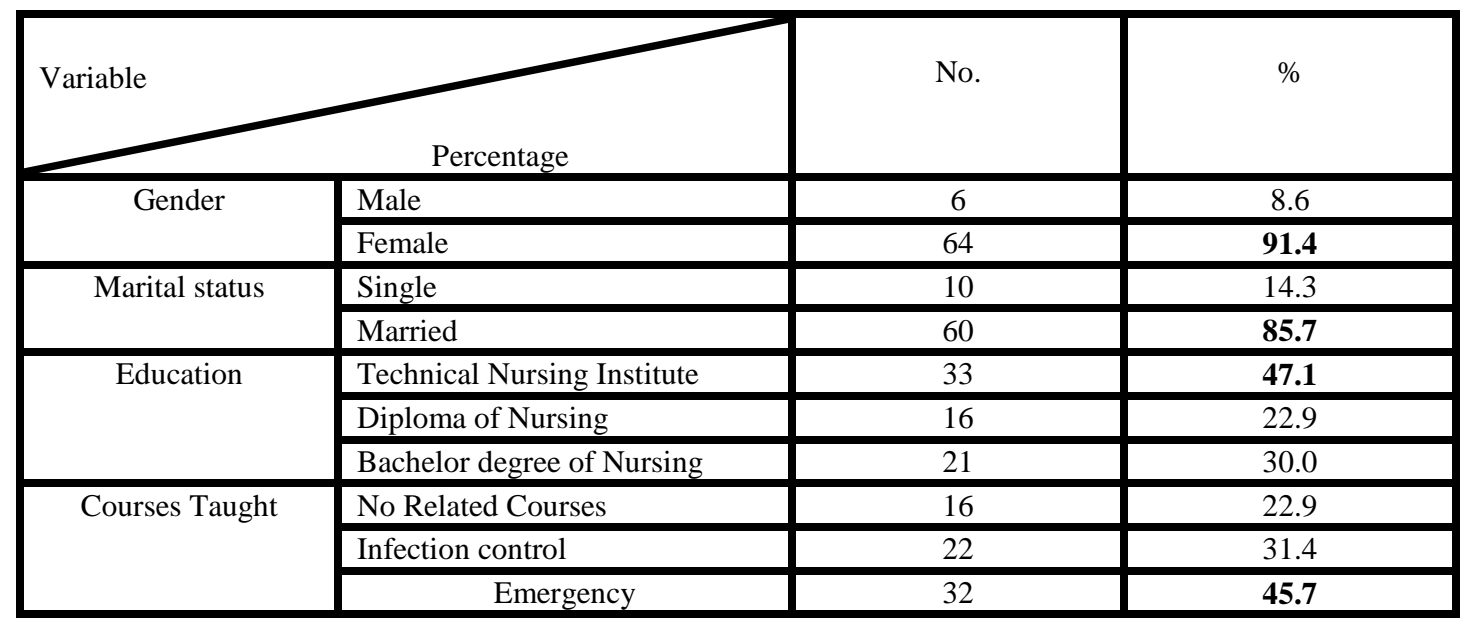

As show from table (1) that ,(91.4\%) of the study sample were females .As Well, $(85.7 \%)$ of them were married .While $(47.1 \%)$ of them were having technical nursing institute degree in nursing and $(45.7 \%)$ of them got training courses in emergency courses.

Table (2): Distribution of the studied sample according to levels of knowledge $(n=70)$

\begin{tabular}{|l|l|c|c|c|c|}
\hline \multirow{2}{*}{ No. } & Knowledge dimensions & \multicolumn{2}{l|}{ Satisfactory $(>\mathbf{8 0} \%)$} & \multicolumn{2}{l|}{$\begin{array}{l}\text { Unsatisfactory } \\
(<\mathbf{8 0 \%})\end{array}$} \\
\cline { 3 - 6 } & & No. & $\%$ & No. & $\%$ \\
\hline 1 & General knowledge about acute pain & 0 & 0 & 70 & 100 \\
\hline 2 & Reasons of acute pain & 0 & 0 & 70 & 100 \\
\hline 3 & Factors affecting acute pain & 0 & 0 & 70 & 100 \\
\hline 4 & Symptoms of acute pain & 0 & 0 & 70 & 100 \\
\hline 5 & Effects of acute pain & 0 & 0 & 70 & 100 \\
\hline 6 & Treatment of acute pain & 0 & 0 & 70 & 100 \\
\hline 7 & Nursing care of patient with acute pain & 0 & 0 & 70 & 100 \\
\hline 8 & Complications of acute pain & 0 & 0 & 70 & 100 \\
\hline
\end{tabular}

Table(2) showed that, all the study subjects had unsatisfactory general knowledge about acute pain , reason, factors affecting ,symptoms, effect of acute pain ,treatment nursing care and complication for acute pain. 
Table (3) : Mean and standard deviation (SD) of the total and subtotal knowledge scores of the studied sample $(\mathrm{n}=70)$

\begin{tabular}{|c|c|}
\hline Knowledge dimensions & Mean \pm SD \\
\hline General knowledge about acute pain & $.3464 \pm .21406$ \\
\hline Causes of acute pain & $. \mathbf{4 3 3 3} \pm .29131$ \\
\hline Factors affecting acute pain & $. \mathbf{1 0 0 0} \pm .21869$ \\
\hline Signs \& Symptoms of acute pain & $.2929 \pm .38536$ \\
\hline Effects of acute pain & $.1343 \pm .21188$ \\
\hline Treatment of acute pain & $.1286 \pm .15022$ \\
\hline Nursing care of patients with acute pain & $.2082 \pm .28539$ \\
\hline Complications of acute pain & $.3000 \pm .27305$ \\
\hline
\end{tabular}

Table (3) shows that, the highest mean scores (highest knowledge score of sample) was related to the Causes of acute pain $(0.4333$ out of 1$)$ while the dimension with the lowest mean (lowest knowledge score of sample) was factors affecting acute pain (.1000 \pm .21869$)$.

As regarding the second research question:

Table (4): Distribution of sample according to levels of practice score

\begin{tabular}{|l|l|l|l|l|l|}
\hline No. & Practice dimensions & $\begin{array}{l}\text { Satisfactory } \\
(>\mathbf{8 0 \%})\end{array}$ & \multicolumn{2}{l|}{$\begin{array}{l}\text { Unsatisfactory } \\
(<\mathbf{8 0 \%})\end{array}$} \\
\cline { 3 - 7 } & & No. & $\%$ & No. & $\%$ \\
\hline 1 & Assessment of Pain Intensity\& Character & 0 & 0 & 70 & 100 \\
\hline 2 & Pain Management & 0 & 0 & 70 & 100 \\
\hline 3 & Documentation & 0 & 0 & 70 & 100 \\
\hline
\end{tabular}

Table (4) demonstrates that, hundred percent of the studied sample were having an unsatisfactory practice level in relation to nursing management for acute pain.

Table (5): Mean and standard deviation (SD) of practice score of sample.

\begin{tabular}{|l|c|}
\hline Practice dimensions & Mean \pm SD \\
\hline Description of complaint & $.59 \pm .19$ \\
\hline Pharmacological Management & $.75 \pm .23$ \\
\hline Non Pharmacological Management & $.50 \pm .20$ \\
\hline Documentation & $.00 \pm .00$ \\
\hline Total Mean (out of 32) & $6.74 \pm 1.50$ \\
\hline
\end{tabular}


Table (5) revealed that, the total mean practices score of the studied sample regarding acute pain management $(6.74 \pm 1.50)$. Also, This table illustrates that the highest mean (highest practice score of sample) was Pharmacological Management..

Table (6): Correlation between nurses' knowledge, practice, and age and years of experience

\begin{tabular}{|l|c|c|}
\hline \multicolumn{1}{|c|}{ Variables } & r & p-value \\
\hline Age and knowledge & & 0.3 \\
\hline Experience and knowledge & 0.12 & 0.42 \\
\hline $\begin{array}{l}\text { Experience in Emergency and } \\
\text { knowledge }\end{array}$ & 0.09 & 0.7 \\
\hline Age and practice & 0.04 & 0.08 \\
\hline Experience and practice & 0.21 & 0.4 \\
\hline $\begin{array}{l}\text { Experience in Emergency and } \\
\text { practice }\end{array}$ & 0.24 & 0.7 \\
\hline Total knowledge and total practice & 0.04 & 0.054 \\
\hline
\end{tabular}

As can be seen from table (6) that, there is negative correlation between age, years of experience and knowledge scores $(\mathrm{r}=0.12, \mathrm{p}=0.3),,(\mathrm{r}=0.09, \mathrm{p} 0.42)$ Also, there is negative correlation between age, years of experience and practice scores $(\mathrm{r}=0.21, \mathrm{p}=0.08)$ Also there is no significant statistical correlation between total knowledge score and total practice score $(\mathrm{r}=$ $0.231, \mathrm{p}=0.054)$

\section{Discussion}

Section I: a) Background data of the studied sample:

The total number of the current studied sample was70 nurses; the majority of them were females $(91,4 \%)$. Moreover, near half of the studied sample were having technical nursing institute. The high Percentage of female Technical Nursing Institute is due to the dominance of the females in the nursing profession in Egypt. In relation to age and years of experience, more than two thirds of them age ranged between 20- 30 years and near half of them having $0-5$ years of working experience in nursing and majority of them having $0-5$ years of working experience in emergency department.
This finding is supported by Kizza in some study findings (Kizza,2012) carry out a research entitled nurses' knowledge and practices related to pain assessment in critically ill patients at mulago hospital, Uganda. A total of 170 nurses were interviewed, with $84 \%$ older than 30 yrs. Majority were females (96\%) Majority of the nurses had less than two years of unit experience $(47 \%)$ had attained diploma level of education in nursing. (57\%) had experience of more than ten years in nursing.

Also, this result was agreement with (Bader , 2015) Carry out a research entitled " Critical Care Nurses' Knowledge and practices regarding pain assessment and management. The total number of studied sample was 60 nurses the majority of them 
were females $(83.3 \%)$. Moreover, most of the studied sample carrying diploma nursing degree. Near half of the nurses their age ranged between (20-25 years)and having (1-5 years) of working experiences in nursing and approximately more than half of them having 1-5 years of working experience in the ICU.

This result was disagree with (AL Qadiere\& ALKhalaileh 2014)The results indicate that $51.7 \%$ of participants were male and the average age was 27.2 (SD 4.7) years. In addition, most nurses had a bachelor's degree $(90.5 \%$ )and worked in medical and surgical wards. Furthermore, 52\% of nurses reported no previous pain education in the last five years.

Section II: Nurse' Knowledge regarding pain assessment and management:

In the current study, the finding data that answered the first research question regarding nurses knowledge about assessment and management of acute pain among injured persons revealed that all of the studied subject (100\%)had got unsatisfactory knowledge level with mean $(\mathbf{7 . 8} \pm 5.47)$ out of 37 scores, This finding contradicted with (Willson,2007) Who carry out study about nursing staff knowledge of pain and the result discovered that the research specialist nurses had a more comprehensive knowledge base than the general nurses; however, their knowledge scores did not appear to be related to their experience in terms of years within the nursing profession.

Also, (Ayed, 2015) results disagreed with the study findings, he found that $20.8 \%$ of nurses had good knowledge, about palliative care. Also, (Kassa at al, 2014), showed that $30.5 \%$ of nurses had as good knowledge about palliative care.

This study was agreed with( Yaqoob, 2015) The result of the study showed that a mean score of knowledge was 15.8 out of 33 .This finding indicates that staff nurses had poor knowledge About pain assessment and management.

Contradicting our results( Kizza , 2012) in a study entitled as Nurses' knowledge of the principles of acute pain assessment in critically ill adult patients who are able to self-report found that the mean knowledge score of nurses was $71 \%$ indicating adequate knowledge levels. Also the current study is supported by Jones, et al.,(2004) showed Nurses have insufficient knowledge regarding pain assessment and management.

Also, the current study finding is supported by Willson , 2007\& Jones, et al., (2004) that showed Nurses have insufficient knowledge regarding pain assessment and management strategies

Section III: Nurse' Practices regarding pain assessment and management:

The current study finding that answered the second research question which stated" What are the emergency nurses' practices toward acute pain among injured persons? Revealed that all of the study subjects $(100 \%)$ had got unsatisfactory level of practices. The current study results was agreed with Rose, et,al (2014) Who revealed that more than $80 \%$ of nurses underestimated the patient's pain and they didn't treat it in the correct way.

The study finding regarding pain assessment practices by the studied subjects revealed that nearly all of them didn't assess pain intensity\& character. This finding supported by Kizza , 2007)who revealed that $(78.2 \%)$ of nurses didn't observe patients behavior during pain.

Documentation of pain assessment finding is among the principles of pain management. The finding of this study showed that all nurses didn't document pain scale and vital signs during pain. This finding is supported by( Watt- Watson, et al., 2010)who reported that there is no 
documentation practices among nurses caring for emergency ill persons.

In relation to pharmacological management practices, the majority of nurses are give analgesia it also this finding contraindicated with Watt-Watson, et al.,(2010)who revealed that nurses didn't prescribed analgesic appropriately as the patients who reported moderate to severe pain receive only (47\%) of their prescribed analgesia.

In relation to non Pharmacological management practices, the majority of nurses put the patient in comfortable position. This study supported by (Bicek 2004) who revealed that ( $60 \%$ ) of nurses didn't use non pharmacological measures and the most common therapy used was change of position (53.2). also Polkki et al, (2001)who revealed that (57\%)of nurses used non pharmacological therapies routinely.

\section{Conclusion}

Considering the result of the present study and the available evidence it can be concluded that, hundred percent of the studied sample were having negative correlation and an unsatisfactory knowledge and practice level in relation to nursing management for acute pain. However, there are still some short comings in nurses practice of pain assessment and management. Also documentations of pain characteristic and the outcome of interventions were also inappropriate .

\section{Recommendations:}

Based on the study in the current study it can be recommended:

1- Establishment of in-service training program for nurses included knowledge and skills for how to apply assessment and management of patients with acute pain .

2-Hospital decision makers create strategies to decrease workload on nurses.

3- Follow up nurses' performance in relation to pain management.

4- Establishment of multifaceted approach by Ministry of Health, hospital leadership, nurse leaders, clinical nurses and nurse- educators to; conduct a continuous professional education program on pain assessment for nurses caring for Emergency persons.

5-Introduction of pain assessment tools guidelines and protocols charts for documentation that are appropriate to the setting.

\section{References}

Al Qdire, M., \& AL Khalaileh, M.(2014).Effective ness of Educational Intervention on Jordanian Nurses 'Knowledge and Attitude Regarding Pain Management. British Journal of Medicine \& Medical Research,4(7),1460-1472

Ayed,A.,2015"The Nurses Knowledge and Attitudes towards the Palliative Care " Journal of Education and Practices 6.4: 91-99.

Badr, N, M Morsy, W, Y . Ali, S, N, 2015. Critical care nurses knowledge and practices regarding pain assessment and management at Cairo University Hospitals. Master thes is. Faculty of nursing Cairo University .

Bicek, E.(2004).Nurses' Attitudes, Knowledge, and Use of Non Pharmacological Pain Management Techniques and Therapies "Honors Projects. Paper12. 
Cohens P, Christop, PJ, Morozl ,2004 Pain management in trauma patients. Am J Phys Med Rehabil 83: 142-61

Cordell WH,Keenekk,GilesBK.,Jones JH, Brizendinee J 2012 The high prevalence of pain in emergency medical care. Am J Emerg Med 20(3): 165-9

Elsa Wuhrman, Maureen F. Cooney. Acute Pain: Assessment and Treatment. Medscape. Jan 03, 2011.

Gélinas C, Ross M, Boitor M, Desjardins S, Vaillant F, Michaud C. Nurses' evaluations of the CPOT use at 12-month post-implementation in the intensive care unit. Nurs Crit Care 2014. Nov;19(6):272-280. 10.1111/nicc.12084 [PubMed] [Cross Ref]

Shafeeqa Hasan Yaqoob_1, Husain Ali Nasaif 21Ministry of Health, Kingdom of

Bahrain2 Royal College of Surgeon in Ireland, Medical University of Bahrain,

Kingdom of Bahrain Received: July 5, 2015 Accepted: July 24, 2015 Online : August 10, 2015.

Matthew,E. and Malcom, C.(2007).Nurses' Knowledge and attitude in pain management practices. British Journal of Nursing,16(3)pp 174-179

J.M. John, A. A. Effiong, M. Mgbekem, E. E.,2005 Esienumoh, G. A. Basey, Global Journal of Medical Sciences, 2005, 4(2), $1-7$. Mosby's Dictionary of Medicine,

Kizza, I. B. (2012) Nurses' Knowledge and Practices Related to Pain Assessment Critically ill Patients at Mulago Hospital, Uganda .Masters thesis, Muhimbili University of Health and Allied Sciences.

Neil, M.(2011):Acute pain management part 1 Anatomy \& Physiology Available at http://www.uptodate.com.
Peter, E., Watt-Watson, J. (2002).Unrelieved pain: an ethical and epistemological analysis of distrust in patients. Canadian Journal of Research; 34: 2, 65-80.

Polkki,T., Vehvilainen- Julkunen,K., \&Pietila,A.(2001).Non pharmacological method inrelieving children's postoperative pain : Asurvey on hospital nurses in Finland.Journal of Advanced Nursing,34,483-492.

Rose,L., Haslam,L. ,Dale, C., Knechtel,L., Fraser, M., Pino, R\&Wtt-Watson,J.(2014) Survey of assessment and management of pain for critically ill adults. Intensive and Critical Care Nursing,27(3),121128.Visited at3rd Sptamber2016 Available a http://posterconsultation.esicm.org/module consultation poster/posterDetail.aspx? intld poster $=2940$

Todd K H, Ducharme J, Choiniere M, Crandall cs, Fosnocht d E,Homl p et al 2007 Pain in the emergency department: results of the pain and emergency medicine initiative (PEMI) multicenter study. J Pain 8(6): 460-6

Watt-Watson, J.B. et al (2010). Relationship between nurses' knowledge and pain management outcomes for their postoperative cardiac patients. Journal of Advanced Nursing; 36: 4, 535-545.

Wong, M.(2012).Medical nurses' Knowledge and attitudes regarding pain management.

Woolf CJ \& Ma Q (2007) Nociceptorsnoxious stimulus detectors. Neuron 55(3): 353-64.

Wilson, B. (2007) Nurses knowledge of pain. Journal of Clinical Nursing; 16: 6, 10121020 . 